\title{
A REPORT ON THE SCIENTIFIC WORK OF THE CHICAGO SECTION, 1897-1922*
}

From December, 1896, forward, meetings were held in or near Chicago twice a year regularly, in the spring and during the Christmas holidays.

The number of papers presented at these meetings of the Section is 1,102. If we classify these papers on the basis of the encyclopedic classification, the result is as follows:

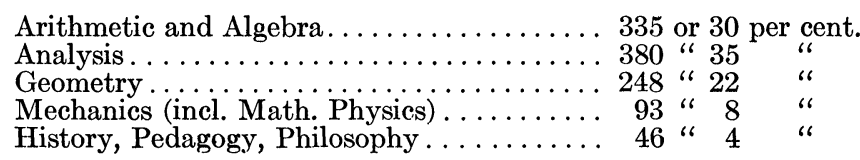

It is found that the 335 papers on arithmetic and algebra were presented by 84 authors, giving an average of 4 papers per author; the 380 papers in analysis, by 135 authors, which is slightly less than 3 papers per author; the 248 papers in geometry, by 118 authors; in mechanics 93 papers, by 33 authors; in history, etc., 46 papers, by 18 authors. While thus the average number of papers presented by each author in each separate field is between 3 and 4 , this average is very misleading. For in the first place, the same author occurs frequently in more than one group, the total number of authors being 278, giving a general average of 4 papers per author. But also this figure gives a very wrong impression of the relative distribution of the papers. For out of the 278 authors, about one half, exactly 133, presented one paper each, i.e., about 10 per cent of the papers. More striking still is the fact that there is a group of 10 authors, constituting less than 4 per cent of the total number, who have contributed 329 papers, which is about 30 per cent of the total; and finally, there is one author who has to his credit 70 of the titles, or over 6 per cent of the total. In view of such extremes, averages mean very little. If one groups the authors according to the number of papers they have presented, the

\footnotetext{
* Parts of a report presented before the Society on April 15, 1922.
} 
number in each group decreases very rapidly as the number of papers per author increases. The result is as follows:

\begin{tabular}{|c|c|c|c|c|c|c|c|c|}
\hline \multicolumn{4}{|c|}{133 authors havino presented } & & \multicolumn{2}{|c|}{1 paper each } & & 133 \\
\hline 43 & 46 & “6 & 6 & 2 & 6 & "6 & $\ldots$ & 86 \\
\hline 24 & " & "6 & " & 3 & " & ، & & 72 \\
\hline 12 & " & "6 & "6 & 4 & "6 & "6 & $\ldots$ & 48 \\
\hline 11 & " & " & " & 5 & " & " & $\ldots \ldots \ldots$ & 55 \\
\hline 14 & "6 & "6 & "6 & 6 & "6 & " & - & 84 \\
\hline 5 & “ & “ & “ & 7 & “ & "6 & $\ldots$ & 35 \\
\hline 3 & " & “ & " & 8 & " & "6 & $\ldots \ldots \ldots \ldots$ & 24 \\
\hline 9 & “6 & 6 & “ & 9 & “ & 6 & $\ldots \ldots \ldots$ & 81 \\
\hline 1 & “6 & “ & “ & 10 & “ & "6 & $\ldots \ldots \ldots \ldots \ldots$ & 10 \\
\hline 3 & " & “ & “ & 11 & “ & 6 & $\ldots \ldots \ldots$ & 33 \\
\hline 5 & “6 & “ & "6 & 12 & "6 & "6 & $\ldots \ldots \ldots \ldots$ & 60 \\
\hline 1 & ، & “ & “ & 13 & " & "، & $\ldots \ldots \ldots \ldots$ & 13 \\
\hline 1 & "6 & "6 & "6 & 14 & "6 & 66 & $\ldots \ldots \ldots \ldots$ & 14 \\
\hline 1 & " & " & " & 15 & " & " & $\ldots \ldots \ldots \ldots$ & 15 \\
\hline 2 & " & " & "6 & 16 & " & "6 & $\ldots \ldots \ldots \ldots \ldots$ & 32 \\
\hline 1 & " & " & " & 19 & "6 & "6 & $\ldots \ldots \ldots \ldots$ & 19 \\
\hline 1 & "6 & "6 & " & 20 & " & 6 & $\ldots \ldots \ldots \ldots$ & 20 \\
\hline 1 & " & " & " & 21 & “ & 6 & $\ldots \ldots \ldots \ldots$ & 21 \\
\hline 1 & “ & “ & " & 24 & " & $" 6$ & $\ldots \ldots \ldots \ldots$ & 24 \\
\hline 1 & a & " & " & 27 & “ & " & $\ldots \ldots \ldots \ldots$ & 27 \\
\hline 1 & "، & "6 & "6 & 32 & "6 & " & $\ldots \ldots \ldots \ldots \ldots$ & 32 \\
\hline 1 & " & "6 & "6 & 35 & "6 & " & $\ldots \ldots \ldots \ldots$ & 35 \\
\hline 1 & "6 & "6 & "6 & 39 & "6 & " & $\ldots \ldots \ldots \ldots$ & 39 \\
\hline 1 & “ & "6 & " & 42 & " & "6 & $\ldots \ldots \ldots \ldots$ & 42 \\
\hline 1 & " & "6 & 6 & 70 & " & " & $\cdots$ & \\
\hline
\end{tabular}

The 10 authors coming last in this group are:

W. D. MacMillan G. A. Bliss $\quad$ F. R. Moulton

E. H. Moore

E. J. Wilczynski

R. D. Carmichael

A. R. Schweitzer

J. B. Shaw

G. A. Miller

L. E. Dickson

If now we inquire as to the publication of these papers, we find that in arithmetic and algebra there have been published 213 out of 335 ( 64 per cent), in analysis 217 out of 380 (57 per cent), in geometry 147 out of 248 (59 per cent), in mechanics 49 out of 93 (53 per cent) and in history, etc., 23 out of 46 (50 per cent) - a total of 649 out of 1,102 (59 per cent).

I shall not attempt to evaluate the relative importance for the work of the Section of published versus unpublished papers. Doubtless there are many papers that have fulfilled their total possible usefulness to author and public when once presented. I do not believe therefore that 100 per cent publication is an end to be too diligently pursued. The 
meetings of the Section would lose a good share of their value if there were no room for airing views, proposing questions, and making suggestions which might not be suitable to appear in print. On the other hand, a small ratio of published to presented papers would not be a sign of the most wholesome development. The figures presented above give but a rough idea of the general character of the published material because they include a variety of journals of varying grade and standard. For that reason it seemed worth while to single out for separate mention the group of papers published in the Transactions. This group consists of 166 papers, which is about one fourth of the published papers, or 15 per cent of the total number of papers presented. It is interesting to note that not a single one of the 21 completed volumes of the Transactions is without several Chicago Section papers, the number averaging 8 per volume and running as high as 12 and 13 in some volumes.

I have thus dwelt somewhat at length upon the papers offered for presentation at the meetings of the Chicago Section, because I feel that this aspect of our meetings is perhaps most widely useful. For a mathematician to know that he can find a group of more or less informed colleagues who will at least listen to what he has to say about his own work, and perhaps comment on it with a measure of understanding of what he is working for, encourage him if he deserves it, discourage him if it be otherwise, must be for him a stimulus of which each one of us can best appreciate the value from his own experience. This value, we will agree, I think, depends to some extent upon the quality and the quantity of our auditors. Since of the former of these characters it is difficult for me to speak, I shall make a brief statement about the latter. The attendance of our meetings is very variable. During the first ten years the number of members present never exceeded 30. Since then it has never fallen below 30 , jumping up to 84 in December, 1908, when the A. A. A. S. met in Chicago, to fall back to 33 at the following meeting in April, 1909 . Since then the attendance at the meetings has grown fairly 
steadily to an average of about 50. A year ago the number went up to 83 , and if our expectations are not disappointed, all previous records will be surpassed on the present occasion. (The attendance at the meeting of April 14 and 15 included 104 members.) But this growth in numbers is but an outward sign of an inner development. And this inner development was the result of careful and thoughtful nurture on the part of those who carried the responsibility.

At the meeting of April, 1897, the Chicago Section was formally organized with E. H. Moore as chairman, T. F. Holgate as secretary, and Professors Ziwet and Hathaway as members of the program committee. In December, 1905, Professor H. E. Slaught was elected secretary of the Section, and he continued to serve in that office for ten years, until December, 1915. No one can appreciate the devotion which he gave to his work as secretary more than his successor does, unless it be those who were associated with him on the program committee. It was during the second decade of its existence that the Section took its big strides forward and all those who, like myself, began to attend the meetings during that time know to how large an extent it was his work that led it forward.

The Section entered upon a period of vigorous development in 1905. A committee was appointed to consider means of improving the meetings of the Section. As a result of the work of this committee, there were held in December, 1907, joint meetings with Sections A and D of the A. A. A. S., including a symposium on the teaching of mathematics to engineers. The following year the Section appointed a committee to study the possibility of improving the character of the mathematical appointments in our colleges and universities, resulting in a report adopted by the Section and a tentative plan proposed by Professor Wilczynski and published in the Bulletin. Joint meetings with the A. A. A. S. and with engineering organizations were held in Minneapolis in 1910, in Cleveland in 1912, in Columbus, Ohio, in 1915, in St. Louis in 1919, and in Toronto in 1921. In April, 1911, 
the Society met in Chicago to hear Professor Bôcher's presidential address. In 1913 the Council of the Society took official notice of the growing importance of the meetings of the Chicago Section by resolving that "the meetings of the Chicago group are henceforth to be designated as meetings of the Society." From 1911 on the retiring chairman delivered an address. When voting in 1913 to make the chairman's address a permanent feature, the Section expressed the opinion "that there are too few papers giving a general survey of any field of mathematics." For a short period, time was set aside on each program for "informal notes and queries" in the hope that in that way more general participation in the discussion might be secured. These different efforts to give the meetings a broader scope led, in 1915, to a proposal by Professor Van Vleck that a symposium be arranged on some topic of wide interest. But it was not until 1917 that the proposal was carried into effect; at that time Professors Bliss and Hildebrandt gave lectures on the Lebesgue Integral. From that time on a symposium address has been given at the April meeting of each year.

ARNold Dresden, Secretary of the Chicago Section.

\section{ELIAKIM HASTINGS MOORE FUND}

BY ARNOLD DRESDENN

A group of former students of Professor E. H. Moore, wishing to use the opportunity afforded by the twenty-fifth anniversary meeting of the Chicago Section to present to Professor Moore a testimonial of their respect and appreciation, brought together a fund to be used for furthering mathematical interest in this country. This fund was contributed to by one hundred and seventy-four persons, former graduate students of mathematics at the University of Chicago, or members of the American Mathematical Society definitely identified with its Chicago Section. On the evening of April 14, 1922, a beautifully bound and illuminated manuscript 